\title{
An In-Vitro Evaluation of Tea and Turmeric Solution on the Color Stability of Nanocomposite and Microhybrid Composites
}

\section{S. Vijay Singh ${ }^{1}$ \\ Vineeta Nikhil $^{2}$}

Sampann Chowdhry ${ }^{3}$

Anil Chandra ${ }^{4}$

\section{INTRODUCTION}

Composite resins were introduced to dentistry nearly half a century ago as an esthetic restorative material. The awareness of the patient to have a restoration that is not only esthetic and natural-looking, but also to have a long life, has made dentistry more challenging. The increasing demand for esthetic dentistry has resulted in rapid development of restorative composite resin in the market. With advances the introduction of nanotechnology to composite resins offers natural esthetics, high biocompatibility, high fracture toughness, superior handling characteristics and excellent durability. The success of these esthetic composite restorations depends upon color match, adhesion to teeth, techniques involving gap-free filling, functional and anatomical contouring and smooth and glossy polish. In addition to the finishing and polishing processes of the final restoration, the dietary and the oral beverages consumed also play an important role on the surface characteristics of composite restoration.

Staining or discoloration is one of the primary reasons for replacement of composite restorations ${ }^{1}$. Discoloration of tooth-coloured, resin-based materials may be caused by intrinsic or extrinsic factors ${ }^{2,3}$.

The discoloration of the resin material can occur as the result of alteration of the resin matrix and of the interface of the matrix and the fillers. The change or oxidation in the amine accelerator, oxidation in the structure of the polymer matrix, and oxidation of the unreacted pendant methacrylate groups can result in discoloration of composite resin ${ }^{4,5}$. Extrinsic factors for discoloration include staining by adsorption or absorption of colorants as a result of contamination from exogenous sources. The degree of discoloration from exogenous sources varies according to the oral hygiene, the eating-drinking and smoking habits of the patients ${ }^{6,7}$.

The staining of composite resins by colored solutions, coffee and tea, nicotine, and beverages has been reported in many previous studies ${ }^{2-8}$. These substances can lead to yellow brown stains in teeth as well as on the surfaces of the resin composites".
Tea and turmeric (Curcuma longa) has been a part of diet since centuries in various part of the world including India. The role of turmeric (curcumin), as an ingredient in common Indian curries spice ${ }^{10}$. Studies reveal that the ability of turmeric to scavenge radicals, reduce iron complex and inhibit peroxidation may explain the possible mechanisms by which turmeric exhibits its beneficial effects in relation to its use in cooking and medicine ${ }^{11}$.

The purpose of this study was to evaluate the staining capacity of nanocomposite and microfilled resin-based composite materials upon exposure to tea and turmeric. The hypothesis of this study was that staining capacity of the resin composite materials is related to the type of the composite and the staining solution used.

\section{MATERIAL AND METHODS}

The present study was conducted to evaluate the effect of tea and turmeric solution on color stability of a nanocomposite and a microfilled composite viz. Z-350[3M, ESPE, USA, Lot no.N10160] and Charisma [Heraeus-Kulzer , Germany, Lot no. 010308]. Sixty Samples were prepared in the form of disc. Cylindrical Teflon molds with dimension $1 \mathrm{~cm}$ in diameter and $1.5 \mathrm{~mm}$ in thickness were taken for the study. The teflon mold was placed on a glass plate with a polyester matrix over it. The composite resin was then placed into the mold, and another polyester matrix and a glass plate placed onto the composite resin surface.

The glass plate was then pressed until it had a tight uniform contact with the plastic mold and extra flash material was removed. The composite resin material was light polymerized for 20 second (Heraeus-Kulzer, USA) placed directly over the mold. Each sample was notched at 2 locations $180^{\circ}$ apart to ensure consistent orientation of the specimens during polishing procedures (double notch on one edge; single notch on the opposite edge).

Samples were oriented in a Teflon fixture so that the instrument was applied in a single direction to simulate intraoral procedure. The direction of polishing was perpendicular to an imaginary line between 2 opposing notches. Finishing and polishing was done by SOFLEX system [3M, ESPE, USA, Lot no.N101067] according to 
manufacturer's instructions with single sided strokes.

The composite material that was used for the study was A3 shade. Sixty (60) samples were made in total from two different types of composites and were randomly divided into 2 group's i.e Group I and Group II.

Group I consisted of 30 samples made from Z-350.

Group II consisted of 30 samples made from Charisma.

Samples of Group I was divided into:

Group Ia: Samples kept in tea solution.

Group Ib: Samples kept in Turmeric solution

Similarly, Group II was divided into:

Group IIa: Samples kept in tea solution.

Group IIb: Samples kept in Turmeric solution

Tea solution was prepared by using 5 tea bags [Tetley, Tata Tea limited, and India] in $500 \mathrm{ml}$ of distilled boiling water for 10 minutes. Turmeric solution was prepared using 5 grams [MDH, Haldi powder, India] in $500 \mathrm{ml}$ of distilled boiling water for 10 minutes. Following protocol was adopted (Figure 1) - specimen were initially stored in artificial saliva [Wet Mouth, ICPA Health products LTD, India, Batch No.CO9002] for 4 hours, then immersed in 500 $\mathrm{ml}$ of solution, stirred for 5minutes and returned to artificial saliva. After 4 hours in saliva, the specimens were again immersed in the solution for 5 minutes under steering, returned to artificial saliva for additional 16 hours, and then submitted to a final 5 minutes immersion in the solution. The samples were subjected to four strokes using distilled water and extra soft tooth brush (STIM UNIQUE, INDIA) to and fro along the direction of the notch with light pressure, thus ending the cycle. During the above procedure all the samples were suspended and completely immersed in the solution by a piece of dental floss attached to the orientation nub. The disk was held in a vertical position to minimize the accumulation of sediment on the surface (Figure 2). During the above procedure all the samples were kept in artificial saliva at $37^{\circ} \mathrm{C}$ and for tea and turmeric solution at $50^{\circ} \mathrm{C} \pm 1$. The following protocol was followed to simulate the oral condition. Following removal from the solution, the samples were rinsed with distilled water. The samples were then wiped dry with tissue paper. Any accumulated surface sediment was thus removed. The samples were then observed and recorded for staining at 7 and 21 days.

A blind study was used to avoid any operator prejudice during the observation. The color of all samples was observed after emersion with a photo spectrometer [Tata Color, India]. Color changes were calculated by using the formula, Change in color $\Delta \mathrm{E}=\left(\Delta \mathrm{L}^{2}+\Delta \mathrm{b}^{2}+\Delta \mathrm{a}^{2}\right)^{1 / 2}$

\section{RESULTS}

Minimum discoloration was seen in Charisma after 7 days in turmeric $(\Delta \mathrm{E}=14.79)$ and tea solution $(\Delta \mathrm{E}=3.85)$ [Table 1]. Maximum discoloration was seen in Charisma after 21 days in turmeric $(\Delta \mathrm{E}=36.39)$ and tea solution $(\Delta \mathrm{E}=11.2)$ [Table 2]. When comparing tea and turmeric, turmeric solution showed greater discoloration (Table1 and 2). The difference between the groups was compared statistically (ANOVA and T- Test) and was found to be significant $(\mathrm{P}<.005)$ between all the groups.

\section{DISCUSSION}

Tooth-colored restorative dental materials are continuously exposed to saliva, beverages and food stains in the oral environment; therefore it is important to determine their susceptibility to color change. In this in vitro study solution of tea and turmeric was used as tea and turmeric in has been a part of diet since centuries in various part of the world.

Color stability of the composite resin materials is related to type of the composite resin restorative materials, polishing procedures, the oral hygiene and dietary habits.

Discoloration can be evaluated visually or by instrumental techniques ${ }^{12}$.

Since instrument measurements eliminate the subjective interpretation of visual color comparison, spectrophotometers and colorimeters have been used to measure color change in dental materials ${ }^{13-18}$. The CIE Lab system for measuring chromacity was chosen to record color differences because it is well suited for determination of small color differences 9. The use of the CIE Lab system is also commonly used in dentistry because $\mathrm{L}^{*}, \mathrm{a}^{*}$, and $\mathrm{b}^{*}$ are evenly distributed in a perceptual color space.

When differences in colour matching between humaneye assessment and colorimetric were compared, colour difference was perceptible when $\Delta \mathrm{E}$ values were greater than three ${ }^{19}$. The value of $\Delta \mathrm{E}^{*}$ represents relative colours changes that an observer might report for the materials after immersion or between time periods. Thus $\Delta \mathrm{E}^{*}$ is more meaningful than the individual $\mathrm{L}^{*}, \mathrm{a}^{*}, \mathrm{~b}^{*}$ values $^{20}$.

Intrinsic and extrinsic factors can result in discoloration of tooth-colored resin-based materials. The intrinsic factors involve the discoloration of the resin material itself, such as the alteration of the resin matrix and of the interface of matrix and fillers. Extrinsic factors for discoloration include staining by adsorption or absorption of colorants as a result of contamination from exogenous sources ${ }^{21,22}$. The staining 
of composite resin materials by colored solutions, coffee and tea, nicotine and beverages has been reported ${ }^{14,17,23-25}$. In this study, tea and turmeric was used as a colorant agent because of its frequent consumption in daily life $\mathrm{e}^{10}$.

Staining of composite resin surface is a complex phenomenon that can involve several mechanisms ${ }^{26}$. Finishing and polishing procedures may influence surface smoothness, which is related to early discoloration and rough surfaces mechanically retain surface stains more than smooth surfaces ${ }^{27,28}$. In this study soflex was used to polish the resin disc in both the groups. Color change values equal or larger than 3.7 were considered visually perceptible as well as clinically unacceptable ${ }^{29}$.

Increasing the filler contents of composite resins generally improve the physical, chemical and mechanical properties such as water absorption, color stability and wear resistance. Moreover a high volume fraction of the resin correlates with a high prospect for discolouration ${ }^{30}$. From this study, the amount of matrix resin could not be directly associated with the degree of colour shift. This is in accordance with the observations of Dietchi et $\mathrm{al}^{31}$ who stated that small differences in filler-resin ratio could not be explained by variations in water absorption.

Staining is directly related to the resin phase of composite $^{32}$. Urethane dimethacrylate (UDMA) UDMA based monomers display lower staining values compared to other dimethacrilate based monomer types ${ }^{9}$. The resin systems of Filtek Z350 consist of three primary components; bis-GMA, UDMA, and TEGDMA. However, the resin system of Charisma consist primarily of; bis-GMA, UDMA, and bis-EMA. In these restorative systems, the majority of TEGDMA, a somewhat hydrophilic monomer, has been replaced with a blend of UDMA and bis- EMA4. The low staining susceptibility of Charisma (Heraeus-Kulzer ,Wehrhein, Germany) may be related to a low water sorption rate due to the use of hydrophobic resins. Hydrophilic groups such as the ethoxy group in TEGDMA are thought to show affinity with water molecule by hydrogen bonding to oxygen $^{33}$. This explains for the differences in optical properties due to water exposure might be found in the materials' composition and the way they are affected by environmental conditions. Studies have shown that resinbased composites allow water penetration to matrix or fillermatrix interface ${ }^{34}$. Even though unfilled resin has more resin matrix present than does resin based composite, unfilled resin specimens generally exhibited less colour changes than did resin based composite specimens, with the exception of specimens immersed in cola solution. This demonstrates that the staining solution plays a critical role on the colour changes of composite resins. The present study showed that immersion in Turmeric solution caused a high color change in the specimens after the staining treatment than tea solution. It is not clear why turmeric solution stains more than tea solution. It is likely that the suspension form (10-5 $\mathrm{cm}$ ) of turmeric affects the composite resin surface, increasing pigment deposition and discoloration. However, few studies have evaluated the association between $\mathrm{pH}$ variations and staining ${ }^{35-40}$. However more studies are required to evaluate why turmeric stains more than tea with composite resins.

Study have also showed that the filler particle size and distribution seem to be directly correlated to optical properties and that nanofiller particles provide low visual opacity in non-pigmented dental composites ${ }^{41}$. Moreover, a smaller filler size might contribute to decrease staining and enhance esthetic appearance ${ }^{42}$. According to the manufacturer, Filtek Z350 is a nano composite with a combination of non-agglomerated/non-aggregated $20 \mathrm{~nm}$ silica filler, non-agglomerated/non-aggregated 4 to $11 \mathrm{~nm}$ zirconia filler, and aggregated zirconia/silica cluster filler (comprised of $20 \mathrm{~nm}$ silica and 4 to $11 \mathrm{~nm}$ zirconia particles) and an average cluster particle size of 0.6 to 10 microns. The inorganic filler loading is about $63.3 \%$ by volume. The filler range of charisma a micro-hybride composite is of .02 to 2 microns (Ba glass) and a mean partical size of 0.7 microns. The inorganic filler loading is about $60 \%$ by volume. In case of micro-hybride composite (charisma), when these materials are subjected to abrasion, the resin between and around the particles is lost, leading to protruding filler particles (bumps). Eventually the entire filler particle is plucked from the surface, resulting in craters. These bumps and craters create a roughened surface. In this study the increased staining of micro-hybride composite (charism) after 21 days may be because of rough surface created by plucking of filler particle from the surface. Moreover, large filler particles highly exposed on the surface will produce large surface roughness values ${ }^{43}$. However, with Z350, the nanocluster filler particles consist of loosely bound aggregates of engineered nanofiller particles. The addition of engineered nanoparticles to formulations containing nanoclusters reduces the interstitial spacing of the filler particles leading to higher filler loadings. The filled matrix 
(resin plus engineered nanoparticles) is harder and more wear resistant than resin alone. The increased filler loading results in better physical properties and wear resistance. During abrasion, their wear rate and pattern are more similar to the nanofilled matrix surrounding the clusters therefore smother surface with time as compared with micro-hybrid composite.

\section{FIGURES:}
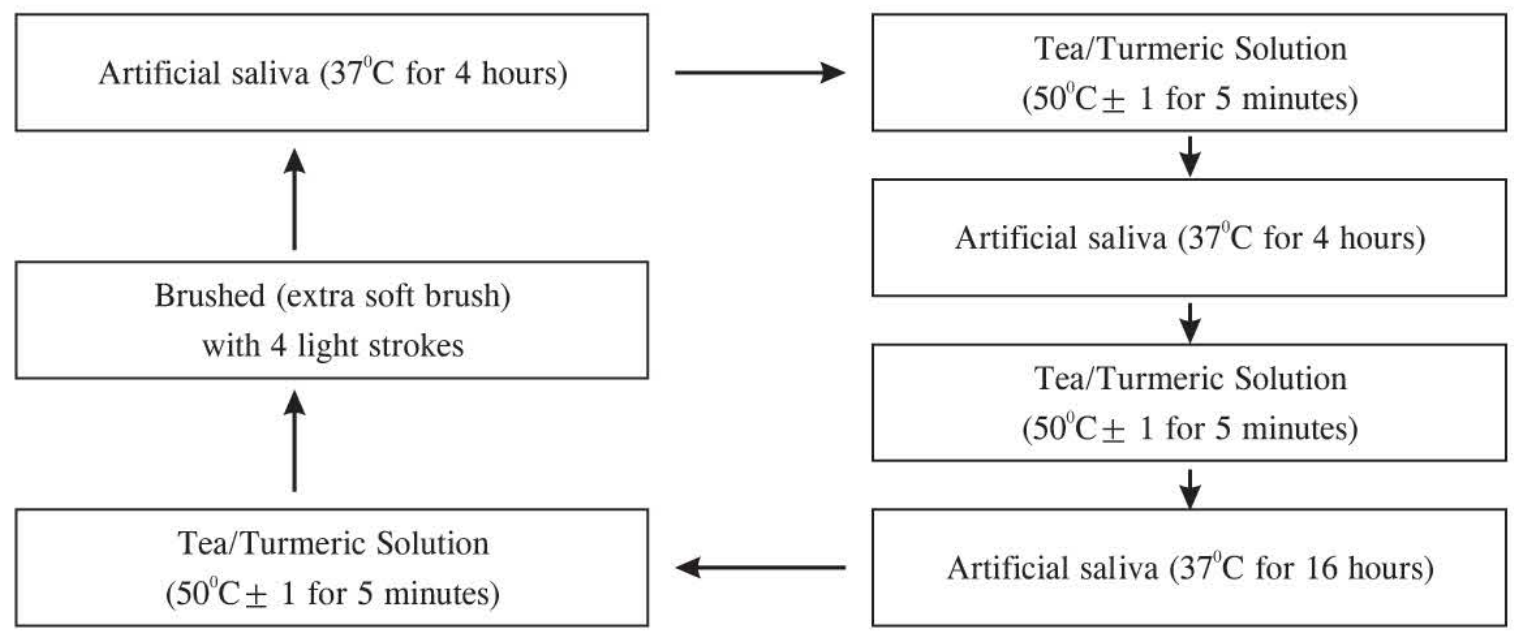

Figure 1: Figure showing testing cycle to simulate the oral condition.

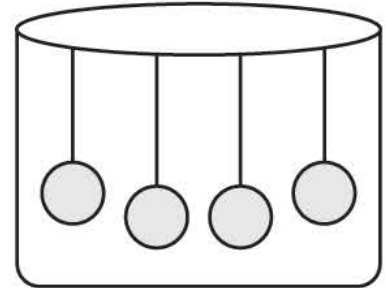

Figure 2: Figure showing solution container with samples suspended in the solution by a piece of dental floss.

\begin{tabular}{|c|c|c|c|c|c|c|c|c|}
\hline \multirow{2}{*}{ 7 DAYS } & \multicolumn{4}{|c|}{$\begin{array}{c}\text { Z-350 } \\
\text { Group I }\end{array}$} & \multicolumn{4}{c|}{$\begin{array}{c}\text { Charisma } \\
\text { Group II }\end{array}$} \\
\hline SOLUTION & $\begin{array}{c}\text { MEAN } \\
{[\mathrm{SD}] \Delta \mathrm{L}}\end{array}$ & $\begin{array}{c}\text { MEAN } \\
{[\mathrm{SD}] \Delta \mathrm{a}}\end{array}$ & $\begin{array}{c}\text { MEAN } \\
{[\mathrm{SD}] \Delta \mathrm{b}}\end{array}$ & $\begin{array}{c}\text { MEAN } \\
{[\mathrm{SD}] \Delta \mathrm{E}}\end{array}$ & $\begin{array}{c}\text { MEAN } \\
{[\mathrm{SD}] \Delta \mathrm{L}}\end{array}$ & $\begin{array}{c}\text { MEAN } \\
{[\mathrm{SD}] \Delta \mathrm{a}}\end{array}$ & $\begin{array}{c}\text { MEAN } \\
{[\mathrm{SD}] \Delta \mathrm{b}}\end{array}$ & $\begin{array}{c}\text { MEAN } \\
{[\mathrm{SD}] \Delta \mathrm{E}}\end{array}$ \\
\hline Tea Group a & -1.30 & -.84 & 6.80 & 6.97 & -1.63 & -0.35 & 3.48 & 3.85 \\
\hline Turmeric Group b & -3.12 & .93 & 16.27 & 16.59 & -3.18 & .79 & 14.43 & 14.79 \\
\hline
\end{tabular}

TABLE 1: Color changes $(\Delta \mathrm{E})$ after 7 days in tea and turmeric solution.

\begin{tabular}{|c|c|c|c|c|c|c|c|c|}
\hline \multirow{2}{*}{ 21 DAYS } & \multicolumn{4}{|c|}{$\begin{array}{c}\text { Z-350 } \\
\text { Group I }\end{array}$} & \multicolumn{4}{c|}{$\begin{array}{c}\text { Charisma } \\
\text { Group II }\end{array}$} \\
\hline SOLUTION & $\begin{array}{c}\text { MEAN } \\
{[\mathrm{SD}] \Delta \mathrm{L}}\end{array}$ & $\begin{array}{c}\text { MEAN } \\
{[\mathrm{SD}] \Delta \mathrm{a}}\end{array}$ & $\begin{array}{c}\text { MEAN } \\
{[\mathrm{SD}] \Delta \mathrm{b}}\end{array}$ & $\begin{array}{c}\text { MEAN } \\
{[\mathrm{SD}] \Delta \mathrm{E}}\end{array}$ & $\begin{array}{c}\text { MEAN } \\
{[\mathrm{SD}] \Delta \mathrm{L}}\end{array}$ & $\begin{array}{c}\text { MEAN } \\
{[\mathrm{SD}] \Delta \mathrm{a}}\end{array}$ & $\begin{array}{c}\text { MEAN } \\
{[\mathrm{SD}] \Delta \mathrm{b}}\end{array}$ & $\begin{array}{c}\text { MEAN } \\
{[\mathrm{SD}] \Delta \mathrm{E}}\end{array}$ \\
\hline Tea Group a & -2.13 & -.33 & 10.42 & 10.64 & -3.30 & -0.07 & 10.67 & 11.2 \\
\hline Turmeric Group b & -4.15 & 1.84 & 29.78 & 30.12 & -6.84 & 3.79 & 35.54 & 36.39 \\
\hline
\end{tabular}

TABLE 2: Color changes $(\Delta \mathrm{E})$ after 21 days in tea and turmeric solution.

\section{CONCLUSIONS:}

Within the limitations of this study, the following conclusions were drawn:

1. The micro-hybrid composite (Charisma) resin restorative materials, which do not contain TEGDMA, were more color stable than the nanocomposite (Filtek Z350) after 7 days, however after 21 days, color changes were observed more with micro-hybrid composite than nanocomposite.

2. The highest color change values were obtained for the specimens kept in turmeric solution for both the groups.

\section{REFERENCE:}

1. Kroeze HJP, Plasschert AJ, Van't Hof MA, Truin GJ. Prevalence and need for replacement of amalgam and composite restorations in Dutch adults. Journal of Dental Research 1990;69:1270-1274. 
2. Um CM, Ruyter IE. Staining of resin-based veneering materials with coffee and tea. Quintessence International 1991; 22:377- 386.

3. Yannikakis SA, Zissis AJ, Polyzois GL, Caroni C. Colour stability of provisional resin restorative materials. Journal of Prosthetic Dentistry 1998;80:533-539.

4. Ruyter IE. Composites- characterization of composite filling materials: reactor response. Advances in Dental Research 1988; 2:122-129.

5. Asmussen E. Factors affecting the colour stability of restorative resins. Acta Odontologica Scandinavica 1983; 41:11-18.

6. Satou N, Khan AM, Matsumae I, Satou J, Shintani H. In vitro colour change of composite- based resins. Dental Materials 1989;5:384 387

7. Raptis CN, Powers JM, Fan PL. Staining of composite resins by cigarette smoke. Journal of Oral Rehabilitation 1982; 9:367-371.

8. Gross MD, Moser JB. A colourimetric study of coffee and tea staining of four composite resins. Journal of Oral Rehabilitation 1977; 4:311-322.

9. Khokhar ZA, Razzoog ME, Yaman P. Colour stability of restorative resins. Quintessence International 1991; 22:733-737.

10. Sinha R, Anderson DE, McDonald SS, Greenwald. Cancer risk and diet in India. Journal of Postgraduate Medicine 2003; 49(3):222-228.

11. Tilak JC, Banerjee M, Mohan H, Devasagayam TP. Antioxidant availability of turmeric in relation to its medicinal and culinary uses. Phytotherapy Research 2004; 18(10):798-804

12. Lee $\mathrm{YK}$, Lim BS, Kim CW. Influence of illuminating and viewing aperture size on the colour of dental resin composites. Dental Materials 2004;20:116-123.

13. Gross MD, Moser JB. A colorimetric study of coffee and tea staining of four composite resins. Journal of Oral Rehabilitation 1977; 4:311322.

14. Güler AU, Kurt S, Kulunk T. Effects of various finishing procedures on the staining of provisional restorative materials. Journal of Prosthetic Dentistry 2005;93:453-458.

15. Güler AU, Yilmaz F, Kulunk T, Güler E, Kurt S. Effects of different drinks on stainability of resin composite provisional restorative materials. Journal of Prosthetic Dentistry 2005; 94:118-124.

16. Okubo SR, Kanawati A, Richards MW, Childress S. Evaluation of visual and instrument shade matching. Journal of Prosthetic Dentistry 1998; 80:642-648.

17. Satou N, Khan AM, Matsumae I, Sata J, Shintani H. In vitro color change of composite-based resins. Dental Materials 1989; 5:384387.

18. Seghi RR, Gritz MD, Kim J. Colorimetric changes in composites resulting from visible-light-initiated polymerization. Dental Materials 1990; 6:133-137.

19. Yap AU, Sim CP, Loh WL, Teo JH. Human-eye versus computerized colour matching. Operative Dentistry 1999; 24:358363.

20. Yannikakis SA, Zissis AJ, Polyzois GL, Caroni C. Colour stability of provisional resin restorative materials. Journal of Prosthetic Dentistry 1998;80:533-539.

21. Iazetti G, Burgess JO, Gardiner D, Ripps A. Color stability of fluoride containing restorative materials. Operative Dentistry 2000; 25:520-525.

22. Paravina RD, Powers JM. Esthetic color training in dentistry. St. Louis Mosby 2004;69-123.

23. Raptis CN, Powers JM, Fan PL, Yu R. Staining of composite resins by cigarette smoke. Journal of Oral Rehabilitation 1982; 9:367-371.

24. Um CM, Ruyter IE. Staining of resin-based veneering materials with coffee and tea. Quintessence International 1991; 22:377-386.
25. Ertas E, Guler AU, Yucel AC, Köprülü H, Guler E. Color stability of resin composites after immersed in different drinks. Dental Material Journal 2006; 25:371-376.

26. Smales RJ, Gerke DC. Clinical evaluation of light-cured anterior resin composites over periods of up to 4 years. American Journal of Dentistry $1992 ; 5: 208-211$.

27. Hachiya Y, Iwaku M, Hosoda H, Fusayama T. Relation of finish to discoloration of composite resins. Journal of Prosthetic Dentistry 1984; 52:811-814.

28. Shintani H, Satou J, Satou N, Hayashihara H, Inoue T. Effects of various finishing methods on staining and accumulation of Streptococcus mutans HS-6 on composite resins. Dental Materials $1985 ; 1: 225-227$.

29. Johnston WM \& Kao EC. Assessment of appearance match by visual observation and clinical colorimetry. Journal of Dental Research 1989; 68:819-822.

30. Bayne SC, Taylor DF. Dental materials The art and science of operative dentistry. Sturdevant CM (Ed.) 3rd. ed. St. Louis: Mosby 1995;206-287.

31. Reis AF, Giannini M, Lovadino JR, Ambrosano GM. Effects of various finishing systems on the surface roughness and staining susceptibility of packable composite resins. Dental Materials 2003;19:12-18.

32. Douglas WH, Craig RG. Resistance to extrinsic stains by hydrophobic composite resin systems. Journal of Dental Research 1982;61:41-43.

33. Arima T, Hamada T, McCabe JF. The effects of crosslinking agents on some properties of HEMA-based resins. Journal of Dental Research 1995;74:1597-1601.

34. Oysaed H, Ruyter IE. Water sorption and filler characteristic of composites for use in posterior teeth. Journal of Dental Research 1986;65:1315-1318.

35. Inokoshi S, Burrow MF, Kataumi M, Yamada T, Takatsu T. Opacity and colour changes of tooth coloured restorative materials. Operative Dentistry 1996;21:73-80.

36. Abu-Bakr N, Han L, Okamoto A, Iwaku M. Color stability of compomer after immersion in various media. Journal of Esthetic Dentistry 2000;12(5) 258-263.

37. Bagheri R, Burrow MF, Tyas M. Influence of food-simulating solutions and surface finish on susceptibility to staining of aesthetic restorative materials. Journal of Dentistry 2005; 33(5) 389-398.

38. Choi MS, Lee YK, Lim BS, Rhee SH, Yang HC. Changes in surface characteristics of dental resin composites after polishing. Journal of Material Science: Material in Medicine 2005;16(4) 347-53.

39. Commission Internationale De L'Eclairage. Recommendations on uniform colour spaces, colour difference equations and psychometric colour terms Paris: Bureau Central de la CIE 1978.

40. Imparato JC, Garcia A, Bonifacio CC, Scheidt L, Raggio DP, Mendes FM. Color stability of esthetic ion-releasing restorative materials subjected to $\mathrm{pH}$ variations. Journal of Dentistry in Children 2007;74(3) 189-193.

41. Mitra SB, Wu D, Holmes BN. An application of nanotechnology in advanced dental materials. Journal of American Dental Association 2003;134(10) 1382-1390

42. Vichi A, Ferrari M, Davidson CL. Color and opacity variations in three different resin-based composite products after water aging. Dental Materials 2004;20(6) 530-534.

43. Maalhagh-Fard A, Wagner WC, Pink FE, Neme AM. Evaluation of surface finish and polish of eight provisional restorative materials using acrylic bur and abrasive disc with and without pumice. Operative Dentistry 2003; (28)734-739. 